\title{
The importance of wetlands for the Greater Spotted Eagle Clanga clanga wintering in the Mediterranean Basin
}

\author{
GRZEGORZ MACIOROWSKI, ANTONIA GALANAKI, THEODOROS KOMINOS, \\ MICHALIS DRETAKIS and PAWEŁ MIRSKI
}

\section{Summary}

The Greater Spotted Eagle is an extremely rare species which is strongly associated with wetlands during the breeding period. The winter habitats of this vulnerable species have not been extensively studied so far, although eagles spend over one third of the year there, and these are therefore also crucial for the conservation of the species. We investigated the distribution of Greater Spotted Eagle wintering grounds in the Mediterranean Basin on the basis of telemetry data from individuals caught in breeding grounds, detailed species counts during wintering in Greece, and a literature search. We found that at least 300-400 individuals (c.15\% of the European population) winter in the Mediterranean Basin, sometimes numbering a few dozen in particular river valleys. Individuals used on average $89.7 \mathrm{~km}^{2}$ home ranges for wintering. The Maxent model of wintering habitats performed with high reliability, indicating that most of the coastline along the Mediterranean Sea and some parts of the Black Sea are suitable for the wintering of this species. The distribution of coastal marshes was the most informative for the model. Compositional analyses done for home ranges of GPS tracked individuals and wintering sites in Greece showed the highest preference for salines and salt marshes but also a high preference for coastal lagoons and water courses. We link wetland preference with the availability of medium size prey, optimal for this species, and prey specialisation common to breeding sites.

\section{Introduction}

The Mediterranean Basin contains broad habitat conditions for about 600 bird species (Cuttelod et al. 2008), including about 300 migratory species, which both migrate over and winter in this region in the millions (BirdLife International 2017a). Many of these species depend on wetlands, which are considered the most threatened habitat in Europe (Mitsch and Gosselink 200o). During the annual cycle, migratory birds spend a significant amount of time in wintering grounds compared to breeding sites. The availability and quality of wintering habitats is therefore crucial for individual survival and population dynamics. Some very rare species may be especially susceptible to habitat loss on migratory stop-over sites and wintering grounds (e.g. Burton et al. 2006). Year-round studies on habitat preferences are therefore crucial for understanding species' needs, and for proper conservation management (Martin et al. 2007). In this study we conducted such an analysis for the Greater Spotted Eagle Clanga clanga (hereafter GSE), which is extremely rare in Europe, and in its whole range classified as 'Vulnerable' (BirdLife International 2017b). In its European nesting grounds, extending from eastern Poland to the Ural Mountains, GSE is closely associated with the distribution of various types of marshes, primarily semi-natural vast fens and transitional moors (Ivanovsky 1996, Lõhmus and Väli 2005, Dombrovski 2005, 2012, Mischenko and Melnikov 2013, Maciorowski and Mirski 2014, Maciorowski et al. 2015a). In these areas its main prey includes various wetland bird species (ducks, 
waders, rails), rodents (e.g. water vole Arvicola amphibius) and amphibians (Graszyński et al. 2002, Väli and Lõhmus 2002, Dombrovski and Ivanovski 2005, Maciorowski et al. 2005, Dombrovski 2010). Drainage of wetlands has been reported as a major cause of their decline and indirectly the reduction of population size may accelerate hybridisation with the Lesser Spotted Eagle Clanga pomarina (Lõhmus and Väli 2005, Maciorowski and Mirski 2014, Maciorowski et al. 2015a).

The population of GSE in central and central-eastern Europe is a short or medium distance migratory (Meyburg et al. 2005). Birds of this population winter in regions of northern Africa, Middle East and southern Europe. The most important African wintering sites are probably located on the border of Sudan and South Sudan as well as in Chad (Maciorowski et al. 2014), while further south it is very infrequent. The other broad wintering area is the Mediterranean Basin, especially the Middle East and southern Europe. In Europe most individuals are seen in Greece, while some are also recorded in Spain, France, Italy, Serbia, Montenegro, Romania and Albania (Hallmann 1989, Francois 1992, Handrinos and Akriotis 1997, Trebušak et al. 1999, Yeatman-Berthelot 2000, Alivizatos et al. 2004, Schneider-Jacoby et al. 2006, De Dochy 2008, Perez-Garcia et al. 2014, De Juana and Garcia 2015, Marco and Pérez-García 2017). In the Mediterranean Basin it also winters in the Asian part of Turkey and in the Middle East, mainly Israel (Allon and Shirihai 1991, Shirihai 1996, Dan et al. 2005, Kirwan et al. 2008a, 2008b). Areas of Greece, Turkey and Israel are the most important wintering grounds of this species in the Mediterranean region.

To date, wintering habitats have not been comprehensively investigated, although their determination may significantly contribute to the protection of this species. GSE spend about five months in their wintering grounds, i.e. a slightly shorter period than in nesting grounds. The period of migration and wintering may be associated with high mortality (Meyburg and Meyburg 2005, Maciorowski et al. 2015b), and thus it should be a conservation focus in order to more effectively protect this threatened species and its habitat.

The aim of this study was to identify the distribution of wintering grounds of the species in the Mediterranean Basin, and to investigate habitat factors determining their attractiveness for the GSE. Similar issues on wintering habitats may also concern other rare and migratory species, therefore the findings of such a study may be important from a broader conservation perspective.

\section{Methods}

\section{General distribution of wintering sites and wintering population number}

General data on the distribution and numbers of the wintering population (dataset_1) were collected by a review of the literature in December 2015 using the Web of Knowledge database, Google Scholar, and Google. Information (location, date, number of wintering individuals) was gathered based on key words: "Greater Spotted Eagle", "Aquila clanga", "Clanga clanga", together with "wintering".

\section{Detailed data on wintering sites gathered through GPS - telemetry}

Between 2011 and 2016 we tagged 20 GSE (adults: six males and one female, juveniles: five males, seven females, one unidentified) with North Star GPS transmitters (30 and 4 og PTTs), Ecotone and Aquila GPS GSM loggers (c.35 g) were attached to Teflon ribbons. Adults were caught in June and July near the nests using the Dho-Gaza method with White-tailed Eagle or Eagle Owl as a decoy. Juveniles were caught at the nest at the very last stage of development ( $7-8$ weeks). All birds were sexed using molecular methods (described in Maciorowski et al. 2015b).

Nine individuals (one adult, eight juveniles) which wintered in the Mediterranean Basin and transmitted their location through at least one whole wintering period constituted dataset_2 and this was used to calculate home ranges. One individual wintered in Israel, where land cover variables were not available, and was therefore omitted in habitat modelling and preference analysis. Further analysis was restricted to the northern part of the Mediterranean Basin as unified and up-to-date land cover data were available for Europe and Turkey only. 


\section{Monitoring of wintering populations}

This dataset was gathered during regular counts of the wintering population of this species in Greece during 2002-2014 (dataset_3). Known and potential wintering sites were monitored from mid-November to mid-March. The number of GSE individuals in particular regions is a median between the minimum and maximum numbers of birds recorded in the period of the study.

\section{Distribution of wintering sites}

In order to identify the distribution of Greater Spotted Eagle wintering sites in the Mediterranean Basin we conducted environmental niche modelling (ENM) in Maxent 3.3.3 k software (Phillips et al. 2006). Input occurrence records were 10,791 GPS fixes from nine tracked individuals. Variables used to predict habitat suitability were the Corine Land Cover 2012 (EEA 2016) rasters (split to each category rasters) and two bioclimatic variables: mean temperature and precipitation of the coldest quarter downloaded with 2.5 minutes resolution from the WorldClim database (Hijmans et al. 2005). In order to validate the models, the datasets of location data for each species were divided into training data ( $75 \%$ of the points) and testing data $(25 \%)$. As the final model of suitable habitat we assumed pixels with a value equal to or greater than the threshold of maximum training sensitivity plus specificity (Liu et al. 2005). Finally, to discard the locations outside the wintering range, the model was clipped in ArcGIS 10.3 with the vector layer of wintering sites extent. This was carried out in the same software by generating a convex hull from the wintering site locations from dataset_I plus a 50-km buffer around it. Finally, the jackknife test was carried out in order to check the variables that gave the best gain in model training. The model was validated by a standard approach with the area under the curve (AUC) value of the receiver operating characteristic (ROC) curves between training and testing data. However, as some researchers have shown limitations of this approach (Lobo et al. 2006), we also used external (to training) datasets to double-check the model. The location of wintering sites from the literature (dataset_I) and our own colour ringing recoveries (individuals different from those tracked with GPS devices) were compared using Cohen's kappa index with the model. Only the ringing recoveries from wintering period were used ( $n=8$ individuals in the $1^{\text {st }}, 2^{\text {nd }}$ and $7^{\text {th }}$ calendar years).

\section{Wintering habitat preferences}

To check which habitat types are important for GSE in wintering grounds we conducted compositional analysis (Aebischer et al. 1993) using wintering areas obtained from dataset_2 and dataset_3, and Corine Land Cover 2012 variables.

Dataset_2 contained from 626 to 1,696 location points per tracked individual $(n=8)$ per wintering season. Point datasets were used to draw each individual's winter home range using the kernel density estimation function at the 95 percentile with ArcMET package tools (Wall 2014) in the ArcGIS 10.3 environment. Then, vectors with home ranges were used to clip selected land cover variables connected with water and wetlands (inland marshes, salt marshes, salines, water courses, water bodies and coastal lagoons). As the available background to habitat used by GSE we used a polygon with GSE wintering extent in the Mediterranean Basin (described in the previous section). Other analogous analysis was done with dataset_ 3 and a polygon from the whole boundary of Greece as the available background. Both compositional analyses were done with the adehabitatHS package (Calenge 2006) in R 3.2.3 software.

\section{Results}

We found that at least 300-400 GSE use the Mediterranean region as wintering grounds. The most important wintering regions include Greece (25-35\% of the Mediterranean population), Israel (c.30\%) and Turkey (13-18\%) (Table 1). Most wintering grounds hold only single 
Table 1. Size of Greater Spotted Eagle wintering population in Mediterranean Basin.

\begin{tabular}{lll}
\hline Country & Years & Number of individuals \\
\hline Albania & $1992-2004$ & 14 \\
Bulgaria & 2010 & $\mathrm{~min} .1$ \\
Croatia & no data & $\mathrm{min} .1$ \\
Montenegro & $2003-2004$ & $\mathrm{~min} .5$ \\
France & no data & $\mathrm{min} .1$ \\
Greece & 2002-2014 & $83-140$ \\
Italy & $2013-2014$ & 15 \\
Israel & $1987-2000$ & $105-136$ \\
Romania & no data & $25-30$ \\
Slovenia & 1998 & $\mathrm{~min} . \mathbf{2}$ \\
Spain & 2001-2014 & $7-15$ \\
Turkey & 1989-2013 & $44-72$ \\
& TOTAL & $303-432$ \\
\hline
\end{tabular}

individuals, although up to several dozen birds may winter together in some major winter sites (see Table $\mathrm{S}_{1}$ in the online Supplementary Material). Detailed counts of GSEs in Greece indicated the permanent presence of this species in all major refuges over many years, although the population size changed in individual seasons, e.g. in the most important wintering ground, the Evros Delta, the number of wintering GSE ranged from 21 and 47 (on average 31 during the 10 seasons of the study) (Table SI). Telemetry data revealed that the size of the winter home range of single individuals ranged from 6.7 to $1522 \mathrm{~km}^{2}$ (mean $89.7 \mathrm{~km}^{2}, n=9$; Figure $\mathrm{Ib}, \mathrm{c}$ ).

Maxent models revealed that suitable wintering sites were distributed along the coastlines of the Mediterranean and Black Seas (Figure 1a). Most of the suitable wintering areas were shown to be located in Greece (Figure 1 b), Turkey (Figure Ic) and Spain. Jackknife tests indicated that bioclimatic variables had better gain in model training than land cover variables (mean temperature of the coldest quarter $>$ precipitation of the coldest quarter $>$ land cover). Out of land cover variables, coastal wetlands (salt marshes and salines) clearly had the greatest contribution in model training ( $37.6 \%$ of model gain). The model showed good reliability, test AUC $=0.938$, while Cohen's kappa index reached 0.78 when tested against wintering sites from the literature (dataset_2, $n=27$ ) and $=1$ when tested against ringing recoveries from winter $(n=5)$.

Detailed compositional analysis of wetland habitats showed significant preferences, both in telemetry-designated home-ranges $(\Lambda=0.003, \mathrm{df}=6, P<0.00001)$ and sites indicated by direct species counts in Greece $(\Lambda=0.0012, \mathrm{df}=6,=P<0.00001)$. Both datasets revealed that salines were the most highly preferred (Table 2 ), while the telemetry dataset also clearly pointed to salt marshes and coastal lagoons as significantly more preferred than other wetland types (Table 2a). The observational dataset also indicated salt marshes, but also inland marshes as the second most preferred habitats for wintering (Table $2 b$ ).

\section{Discussion}

The Mediterranean Basin is a wintering site for at least 300-400 GSE from the European population. The whole European population is estimated at 2,430-3,300 individuals (BirdLife International 2004), concentrated mainly in the European part of Russia and Belarus. The data collected on the size of the wintering population are probably underestimated, since in the literature there is a limited body of information on wintering of the GSE in the Middle East. However, the high number of individuals wintering in Israel suggests that in the neighbouring countries, for which no data are available, the size of wintering populations may be comparable. The literature survey indicated that for this rare species southern Europe may be an important refuge, particularly its south-eastern part, where several hundred birds, most probably of eastern and central European 

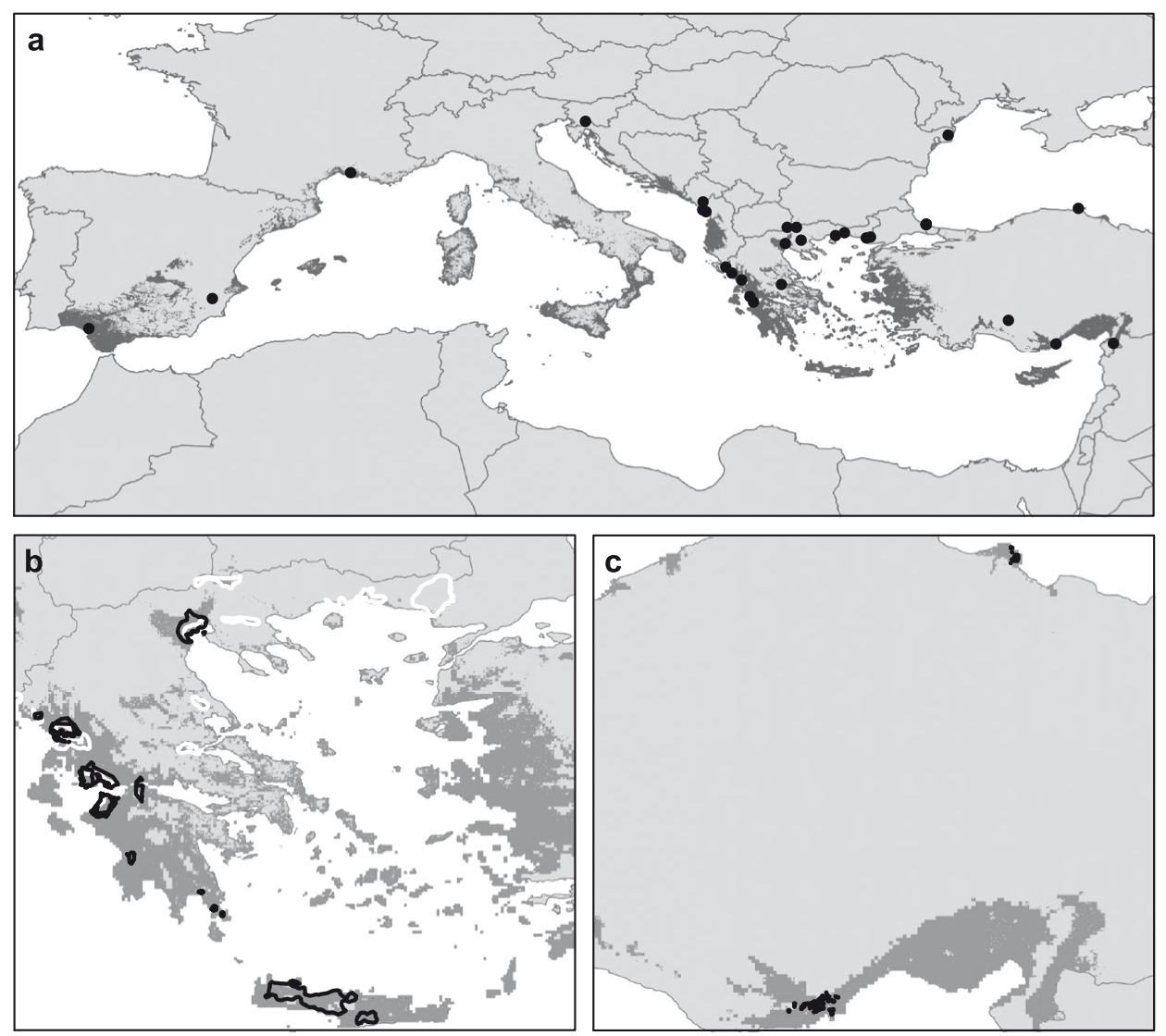

Figure 1. Environmental niche model of Greater Spotted Eagle wintering sites (yellow online, dark gray in print) and (a) locations at which at least two indivuduals were reported wintering in the literature survey (red circles online, black circles in print), (b) known wintering sites of the species in Greece (blue online, white borders in print) and winter home ranges of GPS-tracked Greater Spotted Eagle individuals (red online, black borders in print) in Greece and Turkey (c).

origin spend the winter. Observations of colour-marked and telemetry-monitored birds from Poland in wintering sites in Greece, Turkey, Israel, France and Spain confirm that fact (Dravecký et al. 2008, Maciorowski unpubl. data). The model built on telemetry data strongly agreed with literature data and ringing recoveries from European individuals, and therefore can be used for planning future counts of the wintering population. However, one fact has to be considered - the GSE breeding population is shifting eastwards towards the Mediterranean Basin, and telemetry studies showed GSE are mainly moving south and south-east during the autumn migration (Maciorowski et al. 2014), while only single birds from Estonia and Poland were heading south-west (Pérez-García et al. 2014, Maciorowski unpubl. ringing recoveries). Therefore, we would expect that Turkey, Greece and the Balkans should be explored more often than other suitable habitats in Spain and Italy.

In their wintering grounds in the Mediterranean Basin, GSE used various types of marshes, but most importantly salt marshes, salines and coastal lagoons. Marshland-preference was also observed in Israel, which is one of most important wintering sites for the species. GSE winters there on artificial waterbodies (mostly fish ponds) and in river valleys (managed for agriculture) but is absent from deserts (T. Krumenacker pers. comm.). 
Table 2. Simplified ranking matrices of Greater Spotted Eagle wintering habitat preference comparing (a) habitat use within home-ranges drawn with the kernel95 function vs available habitats in the whole Mediterranean wintering range, (b) habitats in wintering sites designated by direct counts in 2002-2014 in Greece vs wetland habitats in the whole country. Triple sign shows significant deviation from random at $P<0.05$, most preferred habitats appear in bold.

\begin{tabular}{|c|c|c|c|c|c|c|c|}
\hline $\mathrm{a}$ & $\begin{array}{l}\text { Inland } \\
\text { marshes }\end{array}$ & $\begin{array}{l}\text { Salt } \\
\text { marshes }\end{array}$ & Salines & $\begin{array}{l}\text { Water } \\
\text { courses }\end{array}$ & $\begin{array}{l}\text { Water } \\
\text { bodies }\end{array}$ & $\begin{array}{l}\text { Coastal } \\
\text { lagoons }\end{array}$ & Others \\
\hline Inland marshes & $\mathrm{O}$ & $\ldots$ & -- & --- & +++ & --- & +++ \\
\hline Salt marshes & +++ & $\mathrm{o}$ & - & +++ & +++ & + & +++ \\
\hline Salines & +++ & + & o & +++ & +++ & + & +++ \\
\hline Water courses & +++ & -- & -- & o & +++ & $\ldots$ & +++ \\
\hline Water bodies & --- & -- & $-\ldots$ & --- & o & -- & - \\
\hline Coastal lagoons & +++ & - & - & +++ & +++ & o & +++ \\
\hline Others & -- & $-\cdots$ & $\ldots$ & --- & + & $\ldots$ & o \\
\hline $\mathrm{b}$ & $\begin{array}{l}\text { Inland } \\
\text { marshes }\end{array}$ & $\begin{array}{l}\text { Salt } \\
\text { marshes }\end{array}$ & Salines & $\begin{array}{l}\text { Water } \\
\text { courses }\end{array}$ & $\begin{array}{l}\text { Water } \\
\text { bodies }\end{array}$ & $\begin{array}{l}\text { Coastal } \\
\text { lagoons }\end{array}$ & Others \\
\hline Inland marshes & o & - & $-\cdots$ & +++ & +++ & + & +++ \\
\hline Salt marshes & + & o & - & +++ & +++ & + & +++ \\
\hline Salines & +++ & + & o & +++ & +++ & +++ & +++ \\
\hline Water courses &.- & $-\ldots$ & $-\ldots$ & $\mathrm{o}$ & +++ & - & +++ \\
\hline Water bodies & -- & -- & -- & --- & $\mathrm{o}$ & --- & +++ \\
\hline Coastal lagoons & - & - & $-\ldots$ & + & +++ & o & +++ \\
\hline Others & $-\ldots$ & -- & $-\ldots$ & $-\ldots$ & -- & -- & $\mathrm{o}$ \\
\hline
\end{tabular}

Single birds may winter on islands, such as Crete, where they probably primarily scavenge on dead goats and sheep (Maciorowski, pers. obs.). Scavenging behaviour may be underestimated in this species, especially in juveniles, as in the case of Spanish Imperial Eagle Aquila adalberti (Margalida et al. 2017).

A factor affecting the preference of this species for marshes is most probably connected with the availability of an adequate amount of food. In nesting grounds the GSE prefers medium-sized prey such as wetland birds and larger rodents (mainly the water vole and the tundra vole Microtus oeconomus) (Maciorowski et al. 2005, Dombrovski 2010). The similarity of this migratory raptor's diet between nesting and wintering habitats is confirmed by the analysis of the winter food of this species in Greece, where the staple food includes various duck species, Common Moorhen Gallinula chloropus, Coot Fulica atra and small gulls (Alivizatos et al. 2004). Individuals wintering in Israel were most often seen feeding on dead cranes (T. Krumenacker pers. comm.). In scarce wintering sites in Spain this species also prefers marshes, wetlands and coastal lagoon, abundant in waders, coots and rats (Pérez-García et al. 2014). Accordingly, the winter preference of the GSE towards marshes may result from two factors. Firstly, in the landscape transformed by human activity medium-sized prey are much less frequent than in semi-natural wetlands. Secondly, the GSE is a wetland species, and specialisation in the breeding season to hunt a group of prey connected with wetlands makes it easier to use the same group of prey in distant wintering grounds.

The Mediterranean Basin is considered to be one of the 25 Global Biodiversity Hotspots (Myers et al. 2000). It is also a region of very high human population density (455 million), and is an area visited by huge numbers of tourists, amounting to $31 \%$ of European tourist traffic (Cuttelod et al. 2008). Biodiversity in this region is threatened mainly due to the loss of habitats and their degradation, as well as climate change and invasion of alien species (Coll et al. 2010). Marshes in the Mediterranean Basin are frequently isolated ecological islands and are wintering grounds for a considerable part of populations of endangered wetland bird species from the north of the European continent. Due to the abundance of many bird species, the isolation of wetlands, and a large human population density in the Mediterranean Basin, the anthropogenic pressure (tourists, hunters and poachers) in those habitats is probably strong. The protection of marshes in the wintering range may be the key measure aimed at maintaining the population size of this extremely rare species. 


\section{Supplementary Material}

To view supplementary material for this article, please visit https://doi.org/10.1017/ So959270918000047

\section{Acknowledgements}

We would like to thank Piotr Tryjanowski for help in manuscript preparation, Andrzej Batycki, Nikos Bukas, Kordian Bartoszuk, Lacopo Corsi, Matteo Caldarella, Maurizio Medda, Emiliano Mori, Giorgio Paesani, Liviu Parau, Rafał Śniegocki, Sara Whballa, Piotr Zduniak and the Management Authority of the Straits and Estuaries of the Rivers Acheron and Kalamas for their help in field studies. The work was supported by the European Commission LIFE+ fund, the National Fund for Environmental Protection and Water Management, and the Regional Fund for Environmental Protection and Water Management in Białystok within LIFEo8 NAT/PL/Ooo511 AQC Plan "Securing the population of Aquila clanga in Poland: preparation of the National Action Plan and primary site conservation".

\section{References}

Aebischer, N. J., Robertson, P. A. and Kenward, R. E. (1993) Compositional analysis of habitat use from animal radiotracking data. Ecology 74: 1313-1325.

Allon, D. and Shirihai, H. (1991) A survey of wintering raptors in Israel $1987 / 88$. Pp. 46-52 in: D. Yekutiel, ed. Raptors in Israel. Passage and wintering population. Eilat, Israel: International Birdwatching Center.

Alivizatos, H., Papandropoulos, D. and Zogaris, S. (2004) Winter diet of the Greater Spotted Eagle (Aquila clanga) in the Amvrakikos wetlands, Greece. J. Raptor Res. 38: 371-374.

BirdLife International (2004) Birds in Europe: population estimates, trends and conservation status. Cambridge, UK: BirdLife International.

BirdLife International (2017a) Mediterranean / Black Sea Flyway. Factsheet. \http://datazone. birdlife.org/userfiles/file/sowb/flyways/5_ Mediterranean_Black_Sea_Factsheet.pdf.

BirdLife International (2017b) Clanga clanga (amended version of 2016 assessment). The IUCN Red List of Threatened Species 2017: e.T22696027A110443604. http://dx.doi. org/10.2305/IUCN.UK.2017-1.RLTS. T22696027A110443604.en.

Burton, N. H. K., Rehfisch, M. M., Clark, N. A. and Dodd, S. G. (2006) Impacts of sudden winter habitat loss on the body condition and survival of redshank Tringa totanus. J. Appl. Ecol. 43: 464-473.
Calenge, C. (2006) The package adehabitat for the R software: a tool for the analysis of space and habitat use by animals. Ecol. Model. 197: 516-519.

Coll, M., Piroddi, C., Steenbeek, J., Kaschner, K., Ben Rais Lasram, F., Aguzzi, J. et al. (2010) The biodiversity of the Mediterranean Sea: Estimates, patterns, and threats. PLoS ONE 5(8): e11842. doi:10.1371/journal. pone.0011842.

Cuttelod, A., Garcia, N., Malak, D. A., Temple, H. J. and Katariya, V. (2008) The Mediterranean: a biodiversity hotspot under threat. Pp. 1-13 in: J-C. Vié et al, eds. Wildlife in a changing world. The 2008 Review of The IUCN Red List of Threatened Species. Gland, Switzerland: IUCN.

Dan, A., Granit, B., Labinger, Z. and Perlman, Y. (2005) Dynamika zimującej populacji orlika grubodziobego w Izraelu w dolinie rzeki Hula w latach 1996-2005. Pp. 77-79 in T. Mizera and B.-U. Meyburg, eds. International meeting on Spotted Eagles (Aquila clanga, A. pomarina and A. hastata) - research and conservation. Osowiec-Poznań-Berlin.

De Juana, E. and Garcia, E. (2015) The birds of the Iberian Peninsula. London, UK: Helm.

De Dochy, O. (2008) Bird Sites of the OSME Region 5- Birdwatching in the Meriç delta in NW Turkey. Sandgrouse 30: 154-160.

Dombrovski, V. C. (2005) Breeding habitat of the Greater Spotted Eagle Aquila clanga in Belarus and its protection. Pp. $85-87$ in: 
T. Mizera. and B.-U. Meyburg, eds. International meeting on Spotted Eagles (Aquila clanga, A. pomarina and A. hastata) - research and conservation. Osowiec-Poznań-Berlin.

Dombrovski, V.C. (2010) The diet of the greater spotted eagle (Aquila clanga) in Belarusian Polesie. Slovak Raptor J. 4: 23-36.

Dombrovski, V. C. (2012) Greater Spotted Eagle population in Belarus: actual numbers, trends, habitats and occurrence of hybridization with Lesser Spotted Eagle. Pp. 16-17 in P. Mirski, ed. Conservation of the Greater Spotted Eagle. Proceedings of the International Workshop. Goniądz, Poland.

Dombrovski, V. C. and Ivanovski, V. (2005) Number, distribution and breeding ecology of Greater Spotted Eagle (Aquila clanga) in Belarus. Ornithologia 32: 56-69.

Dravecký, M., Sellis, U., Bergmanis, U., Dombrovski, V., Lontkowski, J., Maciorowski, G., Maderič, B., Meyburg, B.-U., Mizera, T., Stój, M., Treinys, R. and Wójciak, J. (2008) Colour ringing of the Spotted Eagles (Aquila pomarina, Aquila clanga and their hybrids) in Europe - a review. Slovak Raptor J. 2: $37-52$.

EEA (2016) Corine Land Cover (CLC) 2012, Version 18.5.1 http://land.copernicus.eu/ pan-european/corine-land-cover/clc-2012.

Francois, J. (1992) Observation sur la présence hivernale de l'aigle criard (Aquila clanga) en Moselle. Ciconia 16: 117-125.

Graszyński, K., Komischke, B. and Meyburg, B.-U. (2002) On the biology of the Greater Spotted Eagle (Aquila clanga Pallas 1811). Pp. $62-75$ in R. Yosef, M. L. Miller and D. Pepler, eds. Raptors in the New Millennium. Eilat, Israel: International Birding and Research Center.

Hallmann, B. (1989) Status and distribution of Aquila in Greece. Biologia Gallo-Hellenica 15: $171-176$.

Handrinos, G. and Akriotis, T. (1997) The birds of Greece. London, UK: Helm.

Hijmans, R. J., Cameron, S. E., Parra, J. L., Jones, P. G. and Jarvis, A. (2005) Very high resolution interpolated climate surfaces for global land areas. Int. J. Climat. 25:1965-1978.

Ivanovsky, V. (1996) Notes on the breeding biology of spotted eagles Aquila clanga and
A. pomarina in Byelorussia. Pp. 397-299 in B.-U. Meyburg and R. D. Chancellor, eds. Eagle Studies. Berlin, London, Paris: World Working Group on Birds of Prey and Owls. Kirwan, G. M., Boyla, K. A., Castel, P., Demirci, B., Özen, M., Welch, H. and Marlow, T. (2008a) The birds of Turkey. London, UK: Helm.

Kirwan, G. M., Özen, M. and Demirci, B. (2008b) Turkey Bird Report 2002-06. Sandgrouse 30: $166-189$.

Liu, C., Pam, M., Dawson, T. P. and Pearson, R. G. (2005) Selecting thresholds of occurrence in the prediction of species distributions. Ecography 28: 385-393.

Lobo, J. M., Jimenez-Valverde, A. and Real, R. (2008) AUC: a misleading measure of the performance of predictive distribution models. Global Ecol. Biogeogr. 17: 145-171.

Lõhmus, A. and Väli, Ü. (2005) Habitat use by the vulnerable greater spotted eagle Aquila clanga interbreeding with the lesser spotted eagle Aquila pomarina in Estonia. Oryx 39: 170-177.

Maciorowski, G., Meyburg, B.-U., Mizera, T., Zub, K. and Matthes, J. (2005) Strategia żerowania i pokarm biebrzańskiej populacji orlika grubodziobego - wyniki wstępne. Pp.133-139 in T.T. Mizera and B.-U. Meyburg, eds. International meeting on Spotted Eagles (Aquila clanga, A. pomarina and A. hastata) - research and conservation. Osowiec-Poznań-Berlin.

Maciorowski, G., Lontkowski, J., Mizera, T. (2014) The Spotted Eagle - vanishing bird of the marshes. Poznań, Poland: Unigraf.

Maciorowski, G. and Mirski, P. (2014) Habitat alteration enables hybridisation between Lesser Spotted and Greater Spotted Eagles in north-east Poland. Bird Conserv. Internatn. 24: 152-161.

Maciorowski, G., Mirski, P., Kardel, I., Stelmaszczyk, M., Mirosław-Świątek, D., Chormański, J. and Okruszko, T. (2015a) Water regime as a key factor differentiating habitats of spotted eagles Aquila clanga and Aquila pomarina in Biebrza Valley (NE Poland). Bird Study 62: 120-125.

Maciorowski, G., Mirski, P. and Väli, Ü. (2015b) Hybridization dynamics between the Greater Spotted Eagles Aquila clanga and Lesser Spotted Eagles Aquila pomarina 
in the Biebrza River Valley (NE Poland). Acta Ornithol. 50: 33-41.

Marco, J. and Pérez-García, J. M. (2017) Águila moteada: Nuevo invernante para la avifauna española. Quercus 372: 12-19.

Margalida, A., Colomeer, M. A., Sánchez, R., Sánchez, F. J., Oria, J. \& González, L. M. (2017) Behavioral evidence of hunting and foraging techniques by a top predator suggests the importance of scavenging for preadults. Ecol. Evol. 7: 4192-4199.

Martin, T. G., Chadès, I., Arcese, P., Marra, P. P., Possingham, H. P. and Norris, R. (2007) Optimal conservation of migratory species. PLoS ONE 2(8): e751. doi:10.1371/journal. pone.0000751.

Meyburg, B.-U. and Meyburg, C. (2005) Tracking the endangered Greater Spotted Eagle. Tracker News 6: 4.

Meyburg, B.-U., Meyburg, C., Mizera, T., Maciorowski, G. and Kowalski, J. (2005) Family break up, departure, and autumn migration in Europe of family of greater Spotted Eagles (Aquila clanga) as reported by satellite telemetry. J. Raptor Res. 39: 462-466.

Mischenko, A. L. and Melnikov, V. N. (2013) The Greater Spotted Eagle in European part of Russia: main nesting areas, size dynamics and threats to the population. Pp. 14-15 in P. Mirski, ed. Conservation of the Greater Spotted Eagle. Proceedings of the International Workshop. Goniądz, Poland.

Mitsch, W. J. and Gosselink, J. G. (2000) Wetlands. New York, USA: Wiley.
Myers, N., Mittermeier, R. A., Mittermeier, C. G., da Fonesca, G. A. B. and Kent, J. (2000) Biodiversity hotspots for conservation priorities. Nature 403: 853-858.

Pérez-García, J. M., Sellis, U. and Väli, Ü. (2014) Winter ranging behaviour of a greater spotted eagle (Aquila clanga) in southeast Spain during four consecutive years. Slovak Raptor J. 8: 23-28.

Phillips, S. J., Anderson, R. P. and Schapire, R. E. (2006) Maximum entropy modelling of species geographical distributions. Ecol. Model. 190: 231-259.

Schneider-Jacoby, M., Schwarz, U., Sackl, P., Dhora, D., Saveljic, D. and Stumberger, B. (2006) Rapid assessment of the ecological value of the Bojana-Buna Delta (Albania/Montenegro). Radolfzell, Germany: Euronatur.

Shirihai, H. (1996) The birds of Israel. London, UK: Academic Press Limited.

Trebušak, M., Rubinič, B. and Vrezec, A. (1999) Spotted Eagle Aquila clanga on Ljubljana moor. Acrocephalus 97: 191-193.

Väli, Ü. and Lõhmus, A. (2002) Parental care, nestling growth and diet in a Spotted Eagle Aquila clanga nest. Bird Study 49: 93-95.

Yeatman-Berthelot, D., ed. (2000) Atlas des oiseaux de France en hiver. Paris, France: Société Ornithologique de France.

Wall, J. (2014) Movement ecology tools for ArcGIS (ArcMET) v.10.3.1. www. movementecology.net.

\section{GRZEGORZ MACIOROWSKI',2, ANTONIA GALANAKI 3 , THEODOROS KOMINOS3, MICHALIS DRETAKIS4, PAWEE MIRSKI ${ }^{2,5 *}$ \\ ${ }^{1}$ Zoological Department, Poznań University of Life Science, Wojska Polskiego 71c, 60-625 Poznań, Poland. \\ ${ }^{2}$ Eagle Conservation Committee, Niepodległości 53/55, 10-044 Olsztyn, Poland. \\ ${ }^{3}$ Raptor Study Group of Greece, Eressou 35, Athens, GR-10681, Greece. \\ 4 Natural History Museum of Crete, School of Science and Engineering, University of Crete, P.O. Box 2208, GR 714 09, Herakleion, Crete, Greece. \\ Institute of Biology, University of Białystok, Ciołkowskiego 1J, 15-245 Białystok, Poland.}

*Author for correspondence; e-mail:p.mirski@uwb.edu.pl

Received 20 April 2017; revision accepted 7 January 2018; Published online 6 April 2018 